Dr Radinko Gligorijević, dipl. inž

Dr Jeremija Jevtić, dipl. inž.

Mr Đuro Borak,

dipl. inž.

IMR-Institut

Beograd

\section{KVALITET BUDUĆIH ULJA ZA MOTORE NISKIH EMISIJA}

UDC: $621.434: 621.892$

Rezime:

U tekućoj dekadi ovog milenijuma proizvođači motora moraju postići dvostruko smanjenje potrošnje goriva, pa time i emisije $\mathrm{CO}_{2} i$ desetostruko smanjenje nivoa emisija, pre svega $\mathrm{NO}_{x}$ i čestica. Za dostizanje tog cilja moraju se razviti nove specifikacije ulja, čiji doprinos smanjenju potrošnje goriva i nivou štetnih emisija postaje sve važniji. Trend razvoja ulja kreće se u pravcu nižih viskoznih gradacija sa nižim sadržajem sumpora, fosfora, sulfatnog pepela i nižom isparljivošću, čime se postiže smanjenje emisije, kao i potrošnje goriva.

Ključne reči: motori SUS, motorna ulja, emisije.

\title{
FUTURE LUBRICANTS QUALITY FOR LOW EMISSION ENGINES
}

Summary:

In the current decade of this millenium automobile manufacturers must achieve an additional twofold increase in fuel efficiency and a tenfold reduction of emission of $\mathrm{CO}_{2}$ and pollutants, especially $\mathrm{NO}_{x}$ and particles. To achieve this goal, a new specification of engine lubricants, whose contribution to fuel efficiency and reduction of emissions cannot be neglected, is to be developed. Development trends in lubricants move towards low viscosity, low content of sulfur, phosphous, sulfate ash and low volatility, resulting in emission reduction and increase of fuel efficiency.

Key words: engines, engine lubricants, emissions.

\section{Uvod}

Smanjenje emisije štetnih polutanata i $\mathrm{CO}_{2}$ kod motora lakih i teških vozila (automobila i kamiona) veliki je problem auto-industrije. Jedan od načina smanjenja ove emisije jeste smanjenje potrošnje goriva na koju direktno utiče potrošnja ulja. Zbog toga je veoma bitno povećati kvalitet ulja koje može obezbediti maksimalnu ekonomičnost potrošnje goriva i veći interval zamene ulja.

Duži interval zamene ulja vrlo je važan kod dugolinijskih kamiona teškaša (šlepera), jer smanjuje troškove za ulje, filtere, organizaciju čuvanja rezervi i dr. Mada su finansijske uštede zbog dužeg intervala zamene motornog ulja znatne, smanjenje potrošnje goriva donosi veće uštede, jer je cena goriva, naročito u kamionskom prevozu, značajnija stavka od cene ulja, s obzirom na to da njihovi dizel motori rade dugi period pod visokim opterećenjem. Neka istraživanja [1-3] na teškim dizel motorima ukazuju da korišćenje sintetičkog motornog ulja SAE 5W40, umesto ,konvencionalnog mineralnog ulja" ili mineralnog baznog ulja „premium“ 15W40, može doneti uštedu 
goriva od 3\%. Podaci kompanije MAN ukazuju na moguću uštedu od $2 \%$, dok podaci Forda (za Mondeo 1,8 1) ukazuju na uštedu od $0,6 \%$ pri korišćenju ulja 5W20 umesto ulja 5W30 [4]. Svaka ušteda goriva donosi i smanjenje štetnih emisija i emisije $\mathrm{CO}_{2}$. ACEA specifikacije A4, B4 i E4 definišu zahteve za ulja benzinskih i dizel motora u pogledu ekonomičnosti potrošnje goriva.

Dakle, pored svih drugih zahteva, od motornih ulja se zahteva smanjenje emisije $\mathrm{CO}_{2}$ emisije izduvnih gasova, pre svih emisije $\mathrm{NO}_{x}$, i emisije čestica $\mathrm{i}$ eliminacija njihovog štetnog uticaja na katalitičke konvertore i senzore u izduvnom sistemu.

Konvencionalna mineralna bazna ulja najčešće se dele prema stepenu zasićenja, sadržaju sumpora i viskozitetnog indeksa i, prema API, svrstavaju se u četiri grupe (tabela 1 ).

Tabela 1

API kategorizacija baznih ulja

\begin{tabular}{|c|c|c|c|c|}
\hline Grupa & $\begin{array}{c}\text { Sadržaj S-a } \\
(\%)\end{array}$ & $\begin{array}{c}\text { Zasićenje } \\
(\%)\end{array}$ & V. I. & $\begin{array}{c}\text { Noack } \\
\%\end{array}$ \\
\hline I & $>0,03$ & $<90$ & $80-120$ & 30 \\
\hline II & $\leq 0,03$ & $\leq 90$ & $80-120$ & 25 \\
\hline III & $\leq 0,03$ & $\leq 90$ & $\geq 120$ & 11 \\
\hline IV & \multicolumn{5}{|l|}{ Svi polialfaolefini (PAO) } & 11 \\
\hline V & \multicolumn{5}{|l}{ Ostala koja nisu uključena u grupe I-IV } & $<11$ \\
\hline
\end{tabular}

Konvencionalna mineralna bazna ulja iz grupe I imaju prilično visok sadržaj sumpora i aromata (do 25\%) i nivo zasićenja preko $75 \%$ (slika 1 ). Sa slike 1 vidi se da ulja iz grupe II imaju znatno manji sadržaj aromata (1\%) u odnosu na ulja iz grupe I.

Sve rigorozniji zahtevi u pogledu radnih uslova i smanjenja emisije, doveli su do ekspanzije sintetičkih motornih ulja čije su prednosti u odnosu na mineralna ulja sledeće:

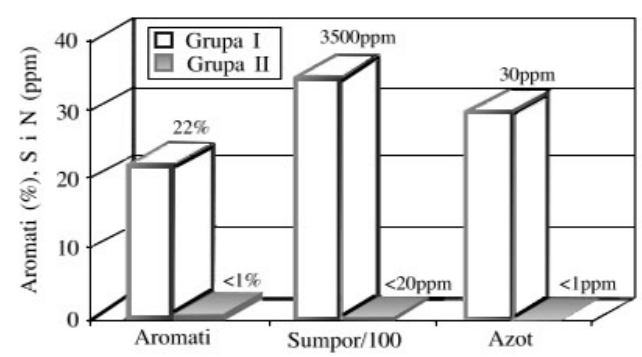

Sl. 1 - Karakteristike ulja grupe I i II prema $A P I^{a} 5^{\circ}$

- veoma dobre reološke karakteristike, kako na niskim, tako i na visokim temperaturama;

- ispunjavaju dva kontradiktorna zahteva - nizak viskozitet i mala isparljivost;

- veoma visoka otpornost na prekid uljnog filma;

- bolja antihabajuća i antizaribavajuća svojstva;

- dobra disperziona svojstva;

- smanjenje potrošnje goriva i ulja,

- produženje perioda zamene;

- visoka otpornost na oksidaciju;

- dobra biorazgradljivost - sintetička ulja koja sadrže estre su $75 \%$ biorazgradiva, dok su mineralna ulja u najboljem slučaju $20 \%$ biorazgradiva;

- niska toksičnost i manja količina produkata sagorevanja (neka sintetička ulja daju 10\% manje azotovih oksida, $15 \%$ manje $\mathrm{CO}$ i $10 \%$ manje $\mathrm{HC}$ ).

Na primer, sintetičko SAE 0W40 u odnosu na mineralno ulje SAE 15W40 smanjuje emisiju čestica za oko $11 \%$, a okside azota oko 5\% [6]. Naša ispitivanja [7] pokazuju slične rezultate, $\mathrm{s}$ tim što se emisija $\mathrm{NO}_{\mathrm{x}}$ smanjuje za oko $12 \%$.

Glavni nedostatak nekih sintetičkih ulja je njihova agresivnost na zaptivke izrađene od materijala na bazi nitrila i akrila, kao i još uvek visoka cena. 
Može se zaključiti da će glavni trend $\mathrm{u}$ razvoju motornih ulja biti:

- korišćenje nižih viskozitetnih gradacija (5W30, 0W30, 0W20) koje smanjuju potrošnju goriva, a time i emisiju $\mathrm{HC}, \mathrm{CO}, \mathrm{NO}_{\mathrm{x}}$, čestica i $\mathrm{CO}_{2}$. Tako, na primer, pri korišćenju ulja $5 \mathrm{~W} 30$, umesto 20W30, potrošnja goriva može se smanjiti do $3 \%$ [8]. U proteklim dekadama trend je bio 20W50 $\rightarrow 15 \mathrm{~W} 40 \rightarrow$ 10W40;

- poboljšanje temperaturne (oksidacione) stabilnosti, što znači smanjenje obrazovanja depozita, a time i smanjenje habanja klipnog sklopa i razvodnog mehanizma;

- produženje perioda zamene ulja (50 $000 \mathrm{~km}$ za putnička vozila i više od $200000 \mathrm{~km}$ za teške kamione);

- smanjenje isparljivosti, što je veoma bitno zbog smanjenja emisije čestica. Tako, na primer, ulje sa isparljivošću $20 \%$ ima $60 \%$ veću emisiju čestica od ulja čija je isparljivost $10 \%$;

- visok indeks viskoziteta;

- nizak sadržaj sumpora $(0,2 \%)$, sulfatnog pepela $(0,5 \%)$ i fosfora $(0,05 \%)$;

- niske emisije i dobra biorazgradivost.

\section{Uticaj ulja na emisiju motora}

Do pre nešto više od jedne decenije potrošnja ulja u motorima bila je, zbog ekonomskih i komercijalnih razloga, uglavnom briga proizvođača motora, rafinerija ulja i proizvođača aditiva.

Sve stroži zakonski propisi o zaštiti životne sredine, a pre svega o smanjenju emisije $\mathrm{NO}_{\mathrm{x}}$ i čestica dizel motora, fokusirali su pažnju na smanjenje potrošnje ulja, čiji doprinos ukupnoj emisiji čestica se ne može zanemariti, naročito kada se sadržaj sumpora u gorivu drastično smanjuje: od 2000 ppm do 2000. godine na sada važećem limitu od $350 \mathrm{ppm}$, do $10 \mathrm{ppm} \mathrm{u}$ 2008. godini (slika 2). Dakle, kako se zakonskim propisima sadržaj $\mathrm{NO}_{\mathrm{x}} \mathrm{i}$ čestica smanjuje tako se i kvalitet ulja povećava. Uticaj ulja na emisiju motora zavisi od fizičko-hemijskih karakteristika ulja od kojih su najvažnije sadržaj sumpora, sulfatnog pepela, aromata $\mathrm{i}$ isparljivost.

Treba istaći da ACEA, u odnosu na API, definiše sledeće kategorije ulja:

- A1-96, A2-96, A3-96, A4-98, A5-02

- za benzinske motore,

- B1-96, B2-96, B3-96, B4-98, B5-02

- za lake dizel motore,

- E1-96, E2-96, E3-96, E4-98, E5-02

- za teške dizel motore.

Jedan od načina za smanjenje izduvnih emisija $\mathrm{NO}_{\mathrm{x}}, \mathrm{HC}$ i čestica pri radu motora jeste ne samo smanjenje potrošnje goriva već i smanjenje potrošnje ulja. Ispitivanja [8-12] pokazuju da ulje znatno utiče na ukupnu emisiju čestica, što prikazuje slika 3 . Kao što se uočava sa slike 3, čestice u izduvnoj emisiji dizel motora nastaju sagorevanjem i isparavanjem goriva (66\%) i sagorevanjem $\mathrm{i}$ isparavanjem ulja (34\%).
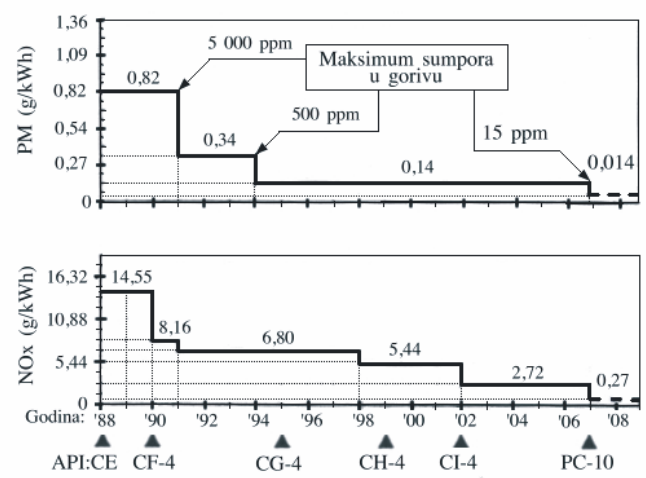

Sl. 2 - Povećanje kvaliteta ulja sa smanjenjem granica emisije ${ }^{a} 9^{\circ}$ 

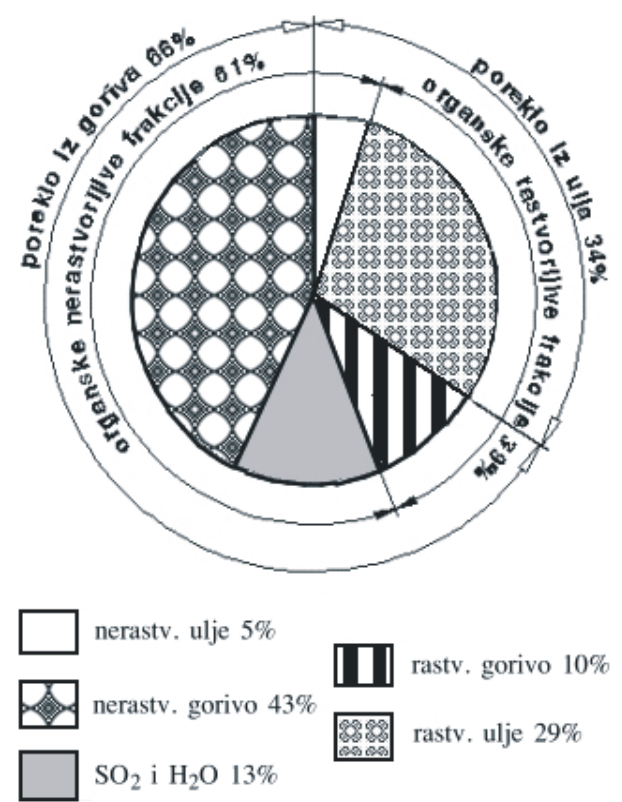

Sl. 3 - Udeo pojedinih frakcija u emisiji čestica pri radu jednog teškog dizel motora ${ }^{a} 11^{\circ}$

Frakcije čestica se, prema rastvorljivosti, mogu podeliti na:

- organski nerastvorljive (INSOLF), koje čine $61 \%$ u ukupnoj masi čestica;

- organski rastvorljive (SOF), čiji je udeo u ukupnoj masti čestica oko $39 \%$.

Organski rastvorljive frakcije sastoje se od visokomolekularnih jedinjenja $(>\mathrm{C} 14)$ koje potiču od nesagorelog goriva i ulja za podmazivanje.

Organski nerastvorljive frakcije sačinjavaju čađ i manji sadržaj metala i sulfati sa vezanom vodom.

Organski nerastvorljive frakcije koje potiču od ulja iznose oko $5 \%$, što približno odgovara $0,027 \mathrm{~g} / \mathrm{kWh}$. Znatno veći udeo ulja nalazi se u organski rastvorljivim česticama - oko $29 \%$, dok je za iste te frakcije udeo goriva oko $10 \%$. Ako se posmatraju samo organski rastvorljive frakcije onda je udeo ulja zna$\tan -$ preko $70 \%$.
Na nivo emisije čestica pri radu dizel motora utiču fizičko-hemijske karakteristike goriva i ulja, konstruktivne karakteristike motora, radni uslovi motora $\mathrm{i}$ potrošnja goriva i ulja. Čestice od ulja potiču sa zidova cilindara motora i zbog propuštanja na vođicama ventila.

Pri radu motora dolazi do prodiranja ulja u cilindar. Deo ulja ne sagori, što takođe doprinosi emisiji čestica. Za smanjenje SOF frakcije u česticama veoma je bitno smanjiti potrošnju ulja u motoru, a ona zavisi od konstrukcije motora, od radnih uslova i od kvaliteta ulja. Potrošnja ulja kamionskih dizel motora kreće se od $6 \mathrm{~g} / \mathrm{h}$, pri lakim uslovima rada i niskom broju obrtaja, do $230 \mathrm{~g} / \mathrm{h}$, pri punom opterećenju i nominalnom broju obrtaja. U odnosu na potrošnju goriva potrošnja ulja se kreće od 0,1 do $0,4 \%$.

\section{Buduća motorna ulja}

Sadašnji zakonski propisi o emisijama lakih i teških vozila sa benzinskim i dizel motorima su umereni u odnosu na predložene - Euro IV i Euro V (slika 4), kao i EPA 04 i EPA 07 (slika 5). Tako strogi zahtevi mogu se ispuniti primenom novih automobilskih tehnologija i kvali-

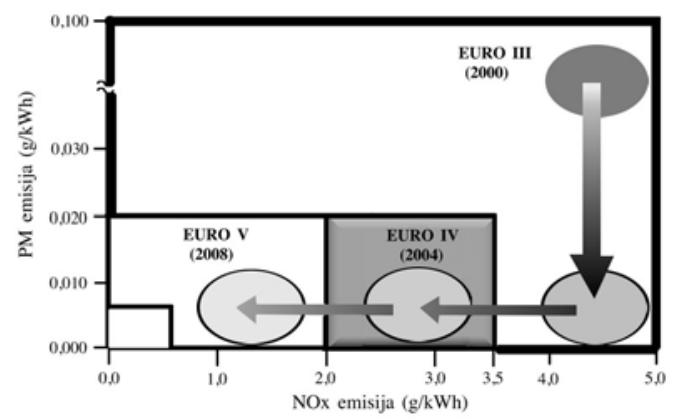

Sl. 4 - Euro IV i Euro V-propisi za emisije koje nastaju pri radu teških dizel motora 


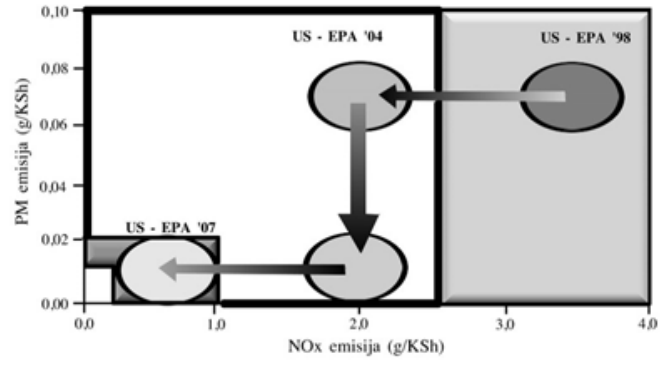

Sl. 5 -US-EPA - propisi za emisije koje nastaju pri radu teških dizel motora

tetnijih goriva i ulja, što ukazuje na to da industrija motora i industrija nafte moraju zajednički raditi radi dostizanja postavljenih granica emisija.

Kao što je poznato, pri radu benzinskih motora emisiona ograničenja postižu se konstrukcionim modifikacijama, kroz sofisticiranu elektronsku kontrolu rada i korišćenjem katalitičkih konventora. Proizvođači motora i vozila nastoje da cena proizvoda bude što manja, pa produžavaju vek konvertora. To otvara pitanje uticaja pojedinih komponenata iz motornog ulja na obrazovanje emisija kao i na trajnost katalitičkih konventora, što je rezultiralo u nacrtu specifikacije ILSAC GF-4 koja ograničava sadržaj fosfora i sumpora u ulju.

Laki dizel motori su dosadašnja emisiona ograničenja postizali novim tehnološkim modifikacijama, uključujući direktno ubrizgavanje, common rail i recirkulaciju izduvnih gasova. Smatra se da ovi motori neće moći da ispune buduće propise bez korišćenja emisionih kontrolnih sistema, uključujući dizel oksidacione katalizatore $\mathrm{za} \mathrm{NO}_{\mathrm{x}} \mathrm{i}$ filtere za dizel čestice. To znači da buduća ulja moraju imati redukujući uticaj na emisije i emisione kontrolne sisteme koji moraju dobro funkcionisati u toku celog veka motora ili u toku pređenih 250000 do
$300000 \mathrm{~km}$. Ovi zahtevi uticaće na formulisanje budućih motornih ulja benzinskih i dizel motora, i odnose se, pre svega, na: sadržaj sumpora, sadržaj fosfora, sadržaj sulfatnog pepela, sadržaj aromata, isparljivost i viskozitet.

U tabeli 2 prikazan je sadržaj sumpora (mas.), fosfora, sulfatnog pepela $\mathrm{i}$ hlora kod nekoliko tipičnih sadašnjih komercijalnih motornih ulja za benzinske i dizel motore putničkih automobila.

Tabela 2

Karakteristike na tržištu najzastupljenijih ulja za benzinske $i$ dizel motore

\begin{tabular}{|c|c|c|c|c|}
\hline Tip ulja & $\begin{array}{c}\text { Sumpor } \\
(\%)\end{array}$ & $\begin{array}{r}\text { Sulfatni } \\
\text { pepeo ( } \%)\end{array}$ & $\begin{array}{l}\text { Hlor } \\
\text { (ppm ) }\end{array}$ & $\begin{array}{c}\text { Fosfor } \\
(\%)\end{array}$ \\
\hline BP Visco 7000 & 0,33 & 1,1 & 199 & \multirow{7}{*}{ 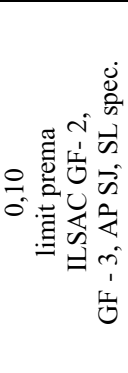 } \\
\hline Castrol SLX & 0,32 & 1,0 & $<10$ & \\
\hline Esso Ultron & 0,32 & 1,4 & 55 & \\
\hline Mobil 1 & 0,10 & 1,1 & 116 & \\
\hline Shell Helix Ultra & 0,26 & 1,3 & 11 & \\
\hline $\begin{array}{l}\text { Texaco } \\
\text { Havoline F3 } \\
\text { Energy }\end{array}$ & 0,36 & - & - & \\
\hline $\begin{array}{l}\text { Total Quartz } \\
9000\end{array}$ & 0,54 & 1,5 & 260 & \\
\hline
\end{tabular}

\section{Sumpor u uljima}

Poznato je da je sumpor inhibitor performansi katalizatora zbog jače absorpcije, i da se „bori“ sa štetnim gasovima za mesto na površini katalizatora. Nivo sumpora u gorivu vrlo je važan faktor za buduća ulja, jer kako se njegov nivo u gorivu smanjuje tako sumpor iz ulja ima sve veći uticaj.

Budući propisi o emisijama motornih vozila imaće bitan uticaj na sastav buducih ulja za benzinske i dizel motore putničkih automobila. Slika 6 ilustruje sastav sadašnjih u odnosu na buduća ulja za benzinske i dizel motore putničkih automobila. 


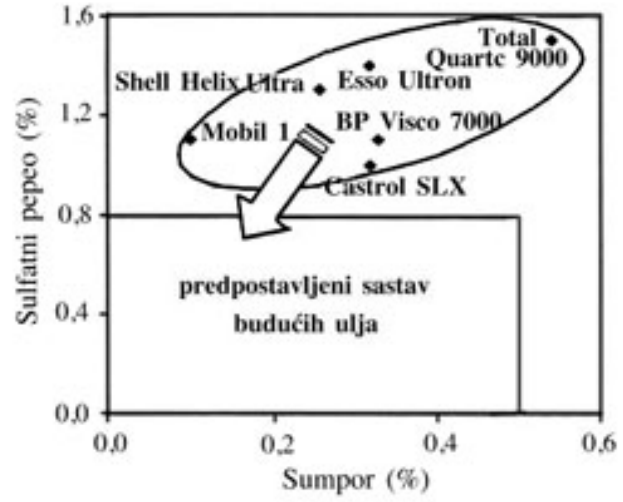

Sl. 6-Sastav sadašnjih komercijalnih ulja u odnosu na buduća ulja za benzinske i dizel motore putničkih automobila

Nedavni predlog specifikacije GF-4 daje granicu sumpora u ulju od $0,5 \%$. Međutim ima mišljenja da bi sadržaj sumpora trebalo ograničiti na $0,2 \%$. Za jedan sasvremeni tipični putnički automobil sa potrošnjom ulja od 40 do $50 \mathrm{~g} / 1000 \mathrm{~km}$, koji koristi gorivo sa 30 ppm sumpora, znači da će učešće sumpora iz ulja biti oko 10\% $\mathrm{u}$ ukupnoj količini sumpora u izduvnom sistemu. Sumpor u motornim uljima potiče, uglavnom, iz: baznog ulja, cinkdialkilditiofosfata (ZnDTP) - antihabajući aditiv, deterdženata na bazi metala, neorganskih modifikatora trenja i nekih inhibitora

Udeo pojedinih izvora sumpora $\mathrm{u}$ ulju prikazan je na slici 7 , a tabela 3 prikazuje procentualni doprinos pojedinih komponenata ulja ukupnom sumporu $\mathrm{u}$ ulju sastava A i B.

Kao što se vidi iz tabele 2, sadržaj sumpora se u sadašnjim komercijalnim uljima kreće od 0,1 do $0,6 \%$, dok se iz tabele 3 vidi da su antihabajući aditivi glavni izvor sumpora.

U tabeli 4 prikazan je sastav nekog budućeg ulja $X$, pri čemu su fiksirani iz- nos sulfatnog pepela $u$ deterdžentu od $0,73 \%$ i fosfora $u$ antihabajućem aditivu od $0,05 \%$.

Tabela 3

Izvori sumpora, sulfatnog pepela i fosfora $u$ motornim uljima

\begin{tabular}{|l|c|c|c|}
\hline $\begin{array}{c}\text { Ulje A } \\
\text { A3 /B3,SJ / CF, } \\
500 / 505,229.1\end{array}$ & $\begin{array}{c}\text { Sumpor } \\
(\%)\end{array}$ & $\begin{array}{c}\text { Sulfatni } \\
\text { pepeo } \\
(\%)\end{array}$ & $\begin{array}{c}\text { Fosfor } \\
(\%)\end{array}$ \\
\hline Deterdžent & 0,14 & 0,95 & 0,0 \\
\hline $\begin{array}{l}\text { Antihabajući } \\
\text { aditivi }\end{array}$ & 0,20 & 0,13 & 0,10 \\
\hline Bazno ulje & 0,41 & 0,0 & 0,0 \\
\hline Ukupno & 0,75 & 1,08 & 0,10 \\
\hline $\begin{array}{l}\text { Ulje B } \\
\text { A3 / B3 / B4, SL / } \\
\text { CF, 229.3 }\end{array}$ & $\begin{array}{c}\text { Sumpor } \\
(\%)\end{array}$ & $\begin{array}{c}\text { Sulfatni } \\
\text { pepeo } \\
(\%)\end{array}$ & $\begin{array}{c}\text { Fosfor } \\
(\%)\end{array}$ \\
\hline Deterdžent & 0,14 & 1,14 & 0,0 \\
\hline $\begin{array}{l}\text { Antihabajući } \\
\text { aditivi }\end{array}$ & 0,19 & 0,13 & 0,09 \\
\hline Bazno ulje & 0,0 & 0,0 & 0,0 \\
\hline Ukupno & 0,34 & 1,27 & 0,09 \\
\hline
\end{tabular}
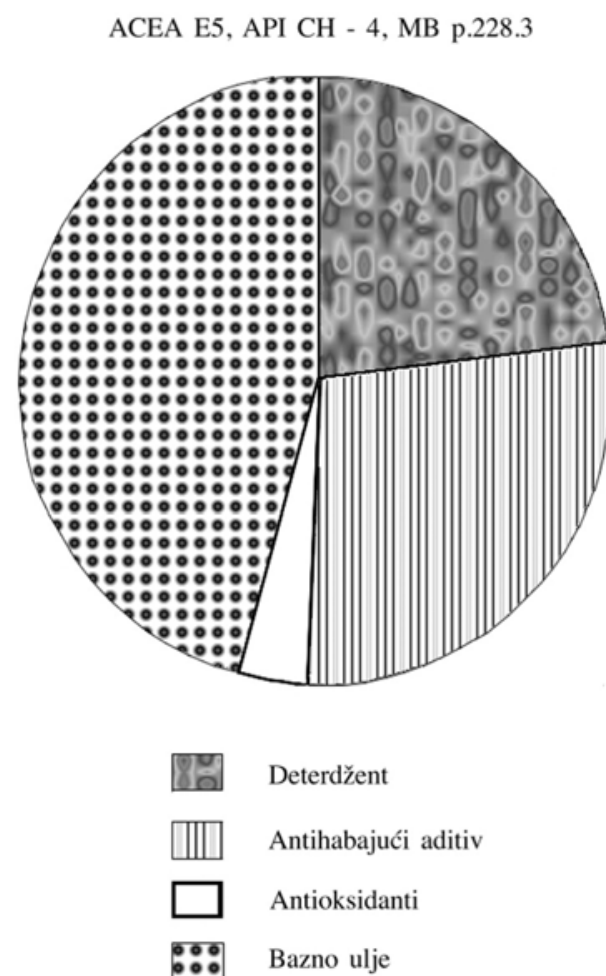

Sl. 7 - Učešće pojedinih izvora sumpora u ulju ${ }^{a} 14^{\circ}$ 
Tabela 4 motore, a $50000 \mathrm{~km}$ za dizel motore (ili

Izvori sumpora, sulfatnog pepela i fosfora $u$ budućim motornim uljima

\begin{tabular}{|l|c|c|c|}
\hline Ulje X & $\begin{array}{c}\text { Sumpor } \\
(\%)\end{array}$ & $\begin{array}{c}\text { Sulfatni } \\
\text { pepeo } \\
(\%)\end{array}$ & $\begin{array}{c}\text { Fosfor } \\
(\%)\end{array}$ \\
\hline Deterdžent & $0,0-0,40$ & 0,73 & 0,0 \\
\hline Antihabajući aditivi & 0,10 & 0,07 & 0,05 \\
\hline Bazno ulje & $0,40-0,0$ & 0,0 & 0,0 \\
\hline Ukupno & 0,50 & 0,80 & 0,05 \\
\hline
\end{tabular}

Kao što su u proteklim dekadama zakonske regulative o emisijama bile generator novih tehnologija u industriji motora i proizvodnji kvalitetnijih goriva i motornih ulja, tako će i buduće specifikacije motornih ulja biti određivane budućim emisionim regulativama.

\section{Sulfatni pepeo u uljima}

Kada pepeo koji potiče iz ulja dospe u izduvni sistem on može obrazovati depozite $u$ emisionim kontrolnim sistemima, smanjujući njihovu aktivnost ili ih čak blokirati. Naročito su filteri za čestice dizel motora osetljivi na sulfatni pepeo.

Tipične vrednosti sadržaja sulfatnog pepela sadašnjih najpoznatijih komercijalnih evropskih ulja za benzinske i dizel motore putničkih automobila kreću se od 1 do $1,5 \%$ (tabela 2). U tabeli 4 prikazan je sadržaj sulfatnog pepela u budućim motornim uljima.

Sulfatni pepeo u uljima (tabela 3) potiče iz deterdženata na bazi metala, antihabajućih aditiva (ZnDTP) i drugih aditiva na bazi metala.

Deterdženti na bazi metala imaju višestruku ulogu u ulju. Ne samo da čiste metalne površine, već i obezbeđuju neutralizaciju kiselina iz goriva i sprečavaju proces degradacije ulja. Tako, na primer, za novu „vectru“, Opel propisuje zamenu ulja na $300000 \mathrm{~km}$ za benzinske dve godine), izuzev ako se godišnje prelazi manje od $5000 \mathrm{~km}$, kada se zamena obavlja posle 12 meseci. Prema tome, smanjenje deterdženata na bazi metala nije lak zadatak, mada ima sugestija da bespepelni disperzanti mogu preuzeti ulogu deterdženata na bazi metala, ali ostaje problematična njihova kompatibilnost sa fluoroelastomernim zaptivkama. Peugeot S.A. u svoje putničke automobile sa dizel motorima ugrađuje filtere za čestice, i preporučuje da se čiste svakih 80000 $\mathrm{km}$. Takođe, Peugeot preporučuje doziranje bespepelnih baznih aditiva u gorivu za olakšanje regeneracije filtera za čestice. Bazirano na 25 ppm koncentraciji metala u gorivu, korišćenje ulja sa $1,1 \%$ sulfatnog pepela $i$ pri potrošnji ulja od $0,15 \mathrm{~kg} / 1000 \mathrm{~km}$ može se izračunati da se za pređenih $80000 \mathrm{~km} \mathrm{u}$ filteru akumulira $230 \mathrm{~g}$ pepela.

Ako se predvidi čišćenje filtera na $160000 \mathrm{~km}$ i dozvoli akumulirani pepeo $\mathrm{u}$ filteru od $200 \mathrm{~g}$, onda bi prihvatljiv sadržaj sulfatnog pepela bio $0,8 \%$. Ipak, očekuje se da sledeća generacija specifikacije ACEA ograniči sulfatni pepeo na $0,5 \%$. Pošto smanjenje sadržaja sulfatnog pepela utiče na produženje veka filtera, treba ograničiti i sadržaj pepela u gorivu. $\mathrm{S}$ obzirom na to da je potrošnja goriva hiljadu do dve hiljade puta veća od potrošnje ulja, to znači da i iznos sulfatnog pepela u gorivu treba da bude toliko puta manji, što iznosi oko $2 \mathrm{mg} / \mathrm{kg}$. Očekuje se predlog da to bude $5 \mathrm{mg} / \mathrm{kg}$, dok su sadašnje vrednosti u gorivu $100 \mathrm{mg} / \mathrm{kg}$.

\section{Fosfor u uljima}

Fosfor je indiciran kao faktor koji utiče na benzinske katalitičke konventore, 
zbog formiranja staklastih depozita. Mada je štetan uticaj na dizel oksidacione katalizatore manji, specifikacije ulja u SAD obraćaju veliku pažnju na nivo fosfora $u$ uljima. Tako, na primer, fosfor smanjuje efikasnost katalizatora za $15 \%$ do $30 \%$.

Tipična vrednost sadržaja fosfora $u$ najrasprostranjenijim evropskim vrstama ulja za benzinske i dizel motore putničkih automobila iznosi 0,10\% ( tabela 2), kako je to i limitirano specifikacijama ILSAC GF-2, GF-3 i API SJ i SL. Za buduća ulja (tabela 6 i 7) predviđa se limit fosfora od $0,05 \%$, kao što je to i u nacrtu specifikacije ILSAC GF-4.

U motornim uljima fosfor potiče iz antihabajućih i antioksidacionih aditiva a naročito iz ZnDTP koji je veoma važan sastojak ulja, tako da njegova zamena uopšte nije jednostavna. Glavni sastojci antihabajućih aditiva bez fosfora baziraju se na sumporu, njihova cena je viša nego ZnDTP, a efikasnost nižeg stepena. Modifikatori trenja omogućavaju da se ovi nedostaci prevaziđu.

\section{Hlor u uljima}

Hlor u uljima nema funkcionalni značaj. On se, uglavnom, pojavljuje kao katalizator $\mathrm{u}$ izvesnim starijim aditivima u procesu proizvodnje, dok ga novije tehnologije ne koriste. Ako je hlor vezan u organskim molekulima, u procesu sagorevanja može dovesti do obrazovanja PCB i dioxina. Neki prozvođači automobila propisiju maksimalni sadržaj hlora $u$ preporučenim uljima. Iz tabele 2 vidi se da neka ulja, kao Castrol SLX i Shell Helix Ultra, sadrže vrlo male količine hlora, dok druga, kao Total i BP Visco, sadrže znatno veće količine hlora.

\section{Aromati u uljima}

Sa povećanjem sadržaja aromata, naročito policikličnih (PAH), emisije čestica od ulja se povećavaju, jer dolazi do kondenzacije PAH na česticama čađi, a sa starenjem ulja ova pojava se intenzivira. Vrednosti PAH su oko dva puta veće kod motora sa indirektnim ubrizgavanjem nego kod motora sa direktnim ubrizgavanjem. Dakle, aromati u ulju utiču na emisije koje nastaju pri radu dizel motora analogno uticaju aromata iz goriva, tj. povećanju emisije $\mathrm{NO}_{\mathrm{x}}, \mathrm{HC}$ i čestica.

Aromati su odgovorni za degradaciju ulja usled oksidacije čiji rezultat je povećanje viskoznosti, pa poboljšanje oksidacione stabilnosti ulja zahteva smanjenje sadržaja aromata.

\section{Isparljivost ulja}

Veoma važna karakteristika ulja, koja utiče na emisiju čestica, jeste $\mathrm{i}$ isparljivost ulja ili Noack vrednost (slika 8). Ulje sa isparljivošću od $15 \%$ ima oko $50 \%$ veću emisiju čestica nego ulje sa isparljivošću od 5\%. Zbog toga Porše za svoje automobilske motore propisuje ulja čija isparljivost mora biti ispod $12 \%$, a ACEA propisuje limite za ulja u zavisno-

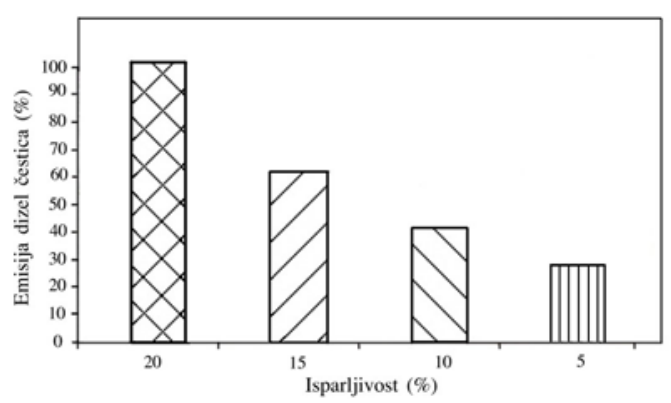

Sl. 8 - Uticaj isparljivosti ulja na emisiju čestica ${ }^{a} 15^{\circ}$ 
sti od viskozitetne gradacije i kvalitetnog nivoa. Na primer, vrednosti su:

A1-96 $\leq 15 \%$ B1-96 $\leq 13 \%$ E1-96 $\leq 13 \%$ A2-96 $\leq 13 \%$ B2-96 $\leq 13 \%$ E2-96 $\leq 13 \%$ A3-96 $\leq 13 \%$ B3-96 $\leq 13 \%$ E3-96 $\leq 13 \%$

Kao ACEA i API propisuje limite za isparljivost $u$ zavisnosti od istih faktora. Na primer:

API SH: SAE 10W30 - 20\%, SAE $15 \mathrm{~W} 40-18 \%$,

ILSAC GF-2 daje 22\% maks, a ILSAC GF-3 daje 15\% maks.

Ulje sa manjom Noack vrednošću daje ne samo manji iznos organskih rastvorljivih već i manji iznos nerastvorljivih frakcija. Sa smanjenjem isparljivosti uglavnom raste viskozitet ulja na mineralnoj bazi, a u znatno manjoj meri na sintetičkoj bazi (slika 9), što je nepovoljno sa aspekta potrošnje ulja, jer sa povećanjem potrošnje ulja raste i emisija $\mathrm{CO}_{2}$. Sa smanjenjem viskoziteta ulja smanjuje se potrošnja goriva, što vodi smanjenju emisije $\mathrm{CO}_{2} \mathrm{i}$ emisije $\mathrm{CO}, \mathrm{HC}, \mathrm{NO}_{x}$ i čestica.

\section{Karakteristike budućih ulja}

Karakteristike budućih ulja za benzinske i dizel motore (tabela 4), zahtevaju i nove testove koji će pratiti proveru kvaliteta budućih ulja (slika 10).

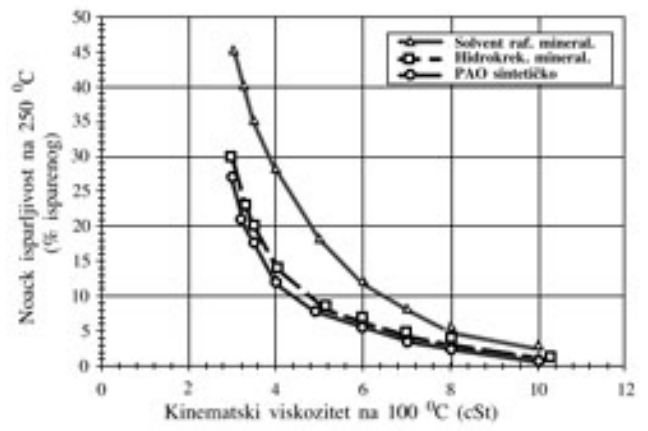

Sl. 9 - Korelacija isparljivosti i viskoziteta ulja ${ }^{a} 16^{\circ}$

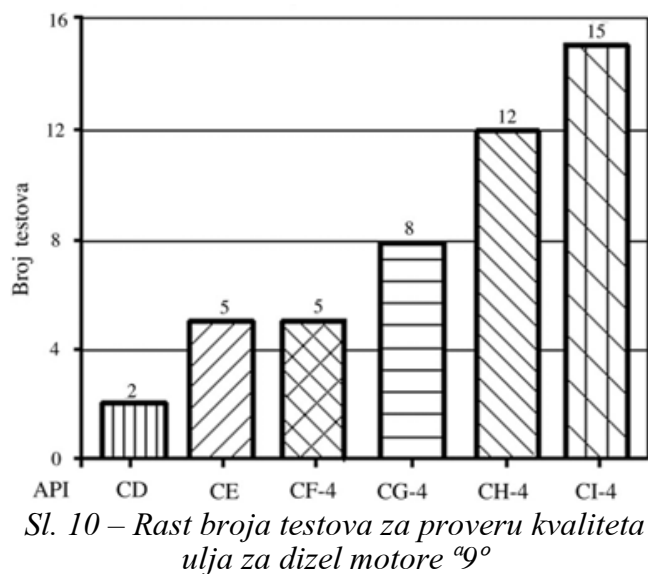

Ulja za benzinske motore

U SAD su zahtevi za niskoemisionim uljima benzinskih motora obuhvaćeni nacrtom specifikacije ILSAC GF-4. Glavne razlike $u$ odnosu na sadašnje specifikacije ILSAC GF-3 odnose se na smanjenje sadržaja fosfora na $0,05 \%$, ograničenje sumpora na $0,5 \%$, uvođenje novog motornog testa za ocenu habanja i zgušnjavanja ulja - sekvenca IIIG. Pored uvođenja starenja u sekvenci VIB, test ekonomičnosti potrošnje goriva biće proširen, a granice pooštrene. Sekvenca IVA test habanja ventila ostaje identična, ali zbog smanjenja sadržaja antihabajućeg aditiva ZnDTP (cinkditiofosfata), to će biti jedan od kritičnih testova. Najzad, test TEOST MHT-4 na probnom stolu biće znatno stroži zbog smanjenja maksimalnog iznosa depozita na $25 \mathrm{mg}$ u odnosu na $45 \mathrm{mg}$ u GF-3.

U Evropi poboljšana specifikacija ACEA 2002 za ulja benzinskih motora, uzima se kao oštra baza za niskoemisione zahteve - za izvesno vreme, mada je sledeće poboljšanje realno očekivati $u$ 2004 godini. Umesto selektivne sekvence 
III F, benzinska sekvenca ACEA oslanja se na PSA TU5 JP-L4 motorni test za povećanje viskoziteta. Postoje dva testa za taloge, sekvenca VG i M111 za crne taloge. Habanje ventila obuhvaćeno je PSA TU3 MS, a ekonomičnost potrošnje goriva testom DCM111 FE.

\section{Ulja za dizel motore}

Habanje brega i klipnog sklopa dizel motora obuhvaćeno je testom na DC OM 602A, kao i povećanje viskoziteta. Odnos između količine čađi i povećanja viskoziteta obuhvaćen je sa PSA XUD 11BTE. Čistoća klipova ocenjuje se korišćenjem VW ICTD, VW TDI i PSA XUD 11, ekonomičnosti potrošnje goriva pomoću M111 FE, a Ford Puma - novi dizel test za ekonomiju goriva biće razvijen u CEC-u.

U tabeli 5 sumirani su navedeni testovi za benzinske i dizel motore (* kritični test, $\mathrm{n} / \mathrm{a}=$ neraspoloživ).

Tabela 5

Motorni testovi za buduća niskoemisiona ulja

\begin{tabular}{|c|c|c|c|}
\hline Ozn.Test & Benzinsk & i motori & Dizel motori \\
\hline Osobine & SAD & Evropa & Evropa \\
\hline Habanje & IVA* & TU3MS & OM $602 \mathrm{~A} *$ \\
\hline $\begin{array}{l}\text { Povećanje } \\
\text { viskoziteta }\end{array}$ & IIIG (n/a) & TU5 * & $\begin{array}{l}\text { XUD 11*, } \\
\text { OM 602A }\end{array}$ \\
\hline Talozi & VG & M111BS * & \\
\hline Čistoća & IIIG, MHT-4* & & TD12* \\
\hline $\begin{array}{l}\text { Ekonomija } \\
\text { goriva }\end{array}$ & VI-B * & M111FE* & $\begin{array}{l}\text { Ford Puma } \\
(\mathrm{n} / \mathrm{a})\end{array}$ \\
\hline
\end{tabular}

\section{Antihabajuće osobine}

Što se tiče antihabajućih osobina ulja sekvenca IVA koristi se za ulja benzinskih motora, a CEC L-51-A-97 (OM $602 \mathrm{~A}$ ) test za ulja dizel motora.
Tabela 6 prikazuje rezultate niskoemisionih ulja sa $0,05 \% \mathrm{P}$ prema $\mathrm{OM}$ 602A (ulje C) i sekvence IVA (ulje Q) u odnosu na referentno ulje (ulje B) prema zahtevima MB p.229.5. Kao što se vidi, nije došlo do povećanog habanja iako je sadržaj fosfora bio dosta nizak.

Tabela 6 Antihabajuće osobine niskofosfornih ulja [17]

\begin{tabular}{|c|c|c|c|c|}
\hline $\begin{array}{l}\text { Granice } \\
\text { Osobine }\end{array}$ & $\begin{array}{l}\text { Predložene } \\
\text { granice }\end{array}$ & Ulje C & Ulje Q & $\begin{array}{l}\text { Ulje B } \\
\text { ref. }\end{array}$ \\
\hline Sumpor (\%) & 0,50 & 0,12 & 0,19 & 0,34 \\
\hline Fosfor (\%) & 0,05 & 0,05 & 0,05 & 0,09 \\
\hline Sulfatni pepeo (\%) & 0,80 & 1,0 & 0,82 & 1,27 \\
\hline OM 602A & B3 Granice & & & \\
\hline $\begin{array}{c}\text { Habanje brega } \\
(\mu \mathrm{m})\end{array}$ & 50,0 & 8,8 & & 30,9 \\
\hline $\begin{array}{l}\text { Uglačanost } \\
\text { cilindra } \\
(\mu \mathrm{m})\end{array}$ & 7,0 & 0,3 & & 0,2 \\
\hline $\begin{array}{l}\text { Habanje cilindra } \\
\qquad(\mu \mathrm{m})\end{array}$ & 20,0 & 9,4 & & 7,4 \\
\hline $\begin{array}{c}\text { Povećanje } \\
\text { viskoznosti } \\
\text { a } 40^{\circ} \mathrm{C}\end{array}$ & 90 & 33 & & 32 \\
\hline Sekvenca IVA & $\begin{array}{c}\text { GF-4 } \\
\text { Granice }\end{array}$ & & & \\
\hline $\begin{array}{c}\text { Habanje brega } \\
(\mu \mathrm{m})\end{array}$ & 120 & & 15,2 & \\
\hline
\end{tabular}

Na slici 11 prikazana je osetljivost motora OM 602A u odnosu na habanje brega nisko emisionih ulja sa smanjenjem sadržaja fosfora (antihabajući sistem-SAW).

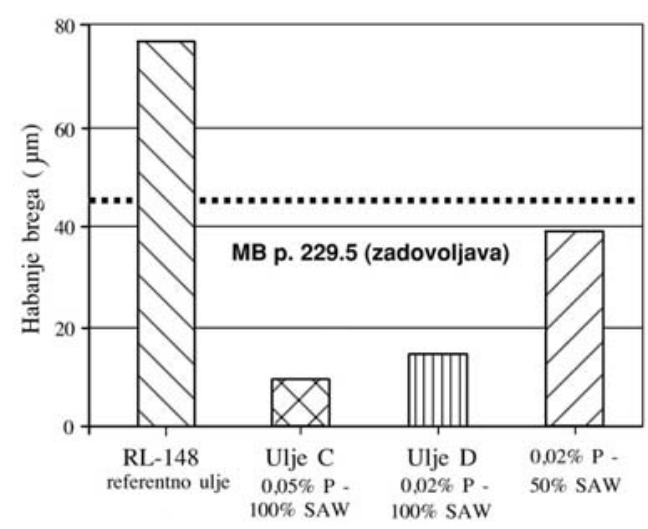

Sl. 11 - Habanje brega po testu OM602A u funkciji sadržaja fosfora u ulju ${ }^{a} 17^{\circ}$ 


\section{Čistoća klipova}

Čistoća klipova se u sekvenci ACEA procenjuje prema motornom testu CEC L-78-T-99 (VW TD12) (54 h, 300 $\left.{ }^{\circ} \mathrm{C}\right)$.

Tabela 7 prikazuje karakteristike ulja (ulje D) sa niskim sadržajem fosfora $(0,02 \%)$, sumpora $(0,7 \%)$ i sulfatnog pepela $(0,95 \%)$.

Karakteristike ulja sa niskim sadržajem

Tabela 7 sulfatnog pepela prema testu VW TDI [18]

\begin{tabular}{|l|c|c|}
\hline Osobine $\quad$ Granice & $\begin{array}{c}\text { Predložene } \\
\text { granice }\end{array}$ & Ulje D \\
\hline Sumpor (\%) & 0,50 & 0,07 \\
\hline Fosfor (\%) & 0,05 & 0,02 \\
\hline Sulfatni pepeo (\%) & 0,80 & 0,95 \\
\hline VW TD12 & B4-98 Granice & \\
\hline Klip & 62 & 61 \\
\hline Klipni prsten & 0,7 & 0,6 \\
\hline
\end{tabular}

Uočava se da ulje D zahteva dalja poboljšanja, ali je indikativno da ulje sa niskim sadržajem sulfatnog pepela ispunjava propisane zahteve.

\section{Oksidaciona otpornost i promena viskoziteta}

Oksidacioni procesi, naročito u području klipnih prstenova, dovode do znatnog povećanja viskoziteta ulja.

Smanjenje fosfora (ZnDTD) i sulfatnog pepela (povećanje sadržaja disperzanata) može dovesti do znatnog smanjenja antioksidacionih karakteristika niskoemisionih ulja.

Antioksidacione karakteristike ulja za dizel motore u sekvenci ACEA procenjuju se prema testu OM 602A. Kao što se vidi iz tabele 6 , ulje $C$ obezbeđuje visok nivo zaštite od povećanja viskoziteta prema MB. p.229.5. Za benzinske motore antioksidacione karakteristike $\mathrm{u}$ sadašnjim sekvencama API i ILSAC pro- cenjuju se motornim testom preko sekvence III (80h, za buduće 160h).

\section{Disperzivnost i kontrola taloga}

Kao što je poznato, čađ se formira u difuznom plamenu pri sagorevanju goriva. Zbog određenog produvavanja, tanak film ulja, pri spuštanju kroz cilindar, meša se sa produktima sagorevanja goriva $u$ zoni klipnih prstenova i na zidovima cilindra, dospevajući u korito motora. Čađ povećava viskozitet ulja, doprinosi obrazovanju depozita, i habanju. Povećanje viskoziteta zbog povećanja sadržaja čađi, procenjuje se motornim testom CEC L56-T-98 (XUD 11BTE). Pri sagorevanju siromašne smeše može doći do formiranja taloga. Oni se procenjuju pomoću dva testa, sekvenca VG i CEC L-53-T-95 (M111 - crni talozi).

\section{Zaključak}

Motorno ulje je postalo važan faktor, pošto, pored ostalog, doprinosi i emisiji štetnih komponenata. U svetu se sve više koriste niskoemisiona ulja, odnosno ulja nižih viskozitetnih gradacija sa niskim sadržajem sumpora, fosfora, sulfatnog pepela i niskom isparljivošću.

Sve stroži zakonski propisi o emisijama vode ka ekspanziji sintetičkih motornih ulja, koja u odnosu na mineralna smanjuju emisiju $\mathrm{NO}_{\mathrm{x}}$ za oko $12 \%$, emisiju čestica za oko $10 \%$ i emisiju $\mathrm{HC}$ za oko $10 \%$, dok potrošnju goriva smanjuju za oko $2 \%$.

Rastući zahtevi u pogledu kvaliteta ulja povećavaju i broj testova za proveru njegovog kvaliteta. 
Zahvaljujući zakonskoj regulativi u prethodnim dekadama kvalitet motornih ulja je povećan. Takođe, i buduće specifikacije motornih ulja biće uslovljene regulativama koje će određivati nivo sledećih emisija.

Literatura:

[1] Kennedy, S. i dr.: A Sinthetic Diesel Engine Oil with Extended Labaratory Test and Field Service Performance, SAE Paper 952553.

[2] Jetter, K. i dr.: Extended Oil Drain Performance Capbilities of Diesel Engine Oils, SAE Paper 982718.

[3] Kelly, K. i dr.: Performance of on Advanced Synthetic Diesel Engine Oil, SAE Paper 2000-01-1993.

[4] Auto Technology Intern. Jan. 2001.

[5] Geehan, J. i dr.: Lubricants that Optimise Diesel Engine Fuel Economy and Allow Extend Oil Drains, 13-th Intern.Colloq. Tribology, Esslingen 2002.

[6] Manni, M. i dr.: Impact of Fuel and Oil Quality on Deposits, Wear and Emissions from a Light-Duty Diesel engine with EG8, SAE Paper 2000-01-1913.
[7] Gligorijević, R., Jevtić, J.: The Impact of Lube Oil Characteristics on Emission from Diesel Engine, Nordtrieb 2002, Stockholm 2002.

[8] Korcek, S. i dr.: Automotive Lubricant for next Millenium, Tribology 2000 plus, Esslingen 2000.

[9] Geehan, J. i dr.: API CI4: The First Oil Category for Diesel Engines Using Cooled Exaust Gas recirculation, 13-th Intern. Colloq. Tribology, Esslingen 2002.

[10] Luther, R.: Cheracheristics of Environmentally Compatible Engine, 13-th Intern. Colloq. Tribology-Lubrication Engineering, Esslingen 2002.

[11] Hilden, L., Mayer, J.: The Cntribution of Engine Oil to Particulate Exhaaust Emissions from high - Duty Diesel Powered Vehicles, SAE Paper 841395, 84.

[12] Lepperhoff, G., Houben, M.: Particulate Emission and Soot Formation Processes by Diesel Engines, I Mech E, 1012,1990 .

[13] Cartellieri, W., Herzog, P.: Swirl Supported of Quiescent Combustion for 1990's Heavy-Duty Diesel EnginesAnalysis, SAE Paper 880342.

[14] Internal Chevron Oronite data.

[15] Luther, R.: Characterists of Environmentally Compatibile Engine Oils, 13-th Intern. Colloq. Trib., Esslingen 2002.

[16] Froelund, K. i dr.: Impact of Oil Consumption on Particulate Emissions for Diesel Engines, Fisita 02, F02 V327.

[17] CEC L-51-A-97 (OM 602 A) Engine tests.

[18] CEC L-78-T-99 Engine tests. 